\title{
Private rooms: Evidence-based design in hospitals
}

I $\mathrm{t}$ almost seems self-evident that there is a link between a patient's psychological and physical recovery and their environment.

But for those who nevertheless doubt it, the evidence proves it.

Yet while evidence-based design of hospitals and health care facilities has become an accepted principle in health architecture circles, it's embryonic in practice.

A relatively small number of health facilities have been constructed using evidence-based design and proponents say the evolving field has still to determine the ideal conditions to promote patient outcomes, staff safety and operational efficiency.

Evidence-based design is defined as the "conscientious, explicit, and judicious use of current best evidence from research and practice in making critical decisions about the design of each individual and unique project" (Hamilton and Watkins, Evidence-Based Design for Multiple Building Types, John Wiley $\&$ Sons, Inc.; 2008). It grew out of pioneering work in 'environmental psychophysiology' (which investigated human transactions with physical environments based on physiological assessments) undertaken by Dr. Roger Ulrich, professor of architecture at Chalmers University in Gothenburg, Sweden.

Ulrich's studies led to publication of a seminal article that indicated surgical patients assigned to rooms with windows looking out on a natural scene had shorter postoperative hospital stays and took fewer potent analgesics than matched patients in similar rooms with windows facing a brick building wall (Science 1984; 27;224[4647]:420-1).

Architects, builders and designers of health care facilities were failing to use evidence to create spaces that promoted healing, Ulrich says. "For many issues there continued to be a lack of quality research findings and something like precedent or best-practice or experience would be the best available evidence. I was well aware of how much was done

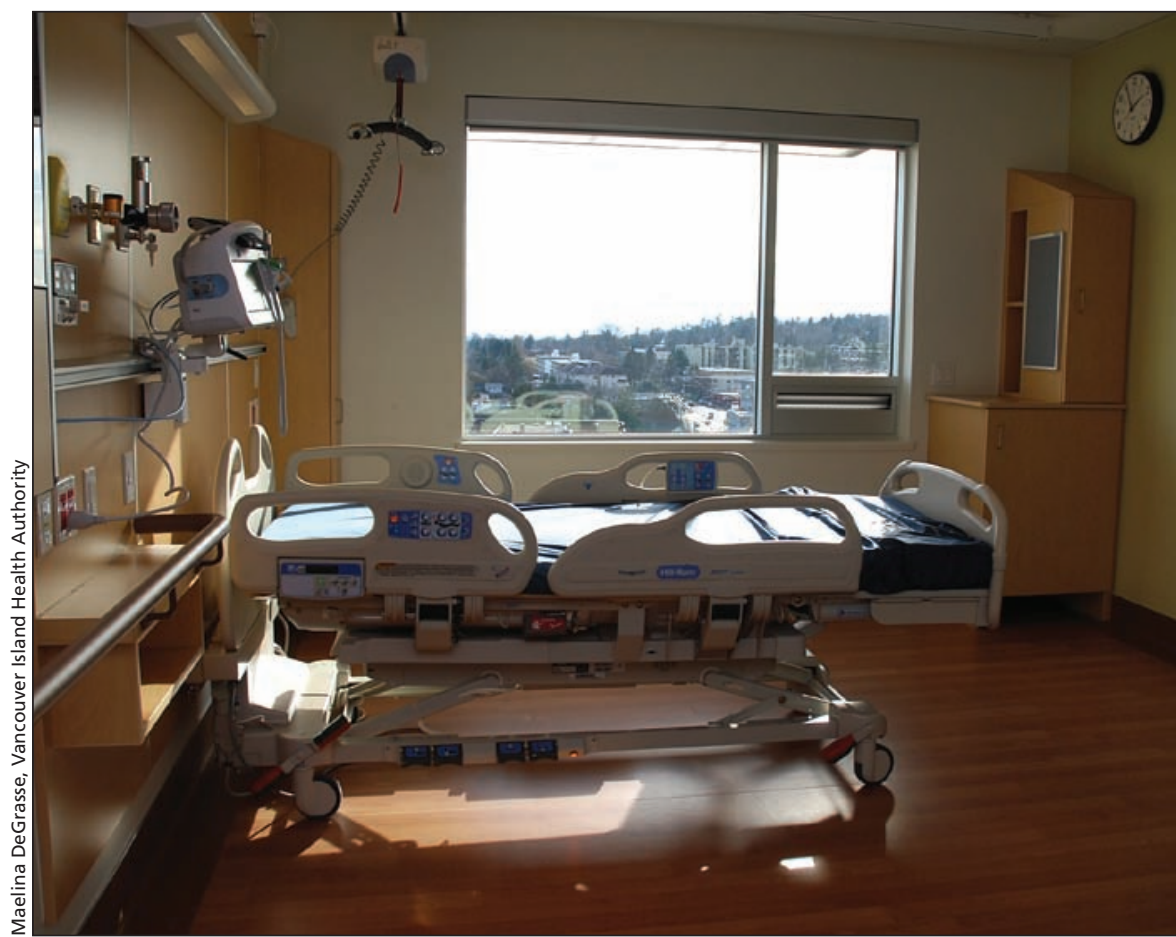

Among the features of rooms at Vancouver Island Health Authority's Royal Jubilee Patient Care Centre in Victoria, British Columbia, are ceiling mounted lifts, colour-contrast environments, external views of nature and handrails.

off of intuition and precedent, and the stakes were simply too high here for that to continue."

"But increasingly if one scanned across the medical and engineering literature ... you could begin to see a lot of areas where some light was being shed, and it was time to recognize this more formally. And I suppose a term [evidence-based design] is one of many ways of doing that."

By 2008, the discipline had exploded. A systematic review indicated there were over 1200 studies, most of which supported the proposition that "well-designed physical settings play an important role in making hospitals safer and more healing for patients and better places for staff to work" (http://hcleader.healthdesign .org/HCLeader_5_LitReviewWP.pdf).

The study also identified several evidence-based interventions for improving outcomes including: the construction of single-bed rooms rather than multi-bed rooms (www.cmaj.ca/lookup /doi/10.1503/cmaj.109-4077); a good acoustic environment; the value of daylight and views of nature; appropriate lighting; better ergonomics; acuityadaptable rooms; as well as improved floor layouts and work settings.

Among the leaders in promoting evidence-based design of health facilities has been the Center for Health Design in Concord, California, which was formed in 1993 to "transform healthcare environments for a healthier, safer world through design research, education, and advocacy" (www.healthdesign.org).

Its efforts include the Pebble Project, which is examining design innovations to determine their impact on health and institutional outcomes. It is "a North American initiative that brings together professionals in the midst of designing or renovating health care spaces to help them learn about what a contemporary healing environment is," says Mark Goodman, vice-president of 
project development for the center and overseer of the project. The aim is to "help drive change in how health care buildings are designed and built."

To that end, it has been involved with 80 organizations, including several in Canada, such as the Trillium Health Centre - Mississauga in Ontario, the St. Michael's Hospital in Toronto, Ontario, the South Calgary Health Campus under construction in Alberta, the British Columbia Children's and BC Women's Redevelopment Project in Vancouver, and the Vancouver Island Health Authority's Royal Jubilee Hospital Patient Care Centre in Victoria, BC. transfer patients, which in turn, reduces back injuries for staff. Some $38 \%$ of all nurses in the United States suffer back injuries at work, according to the American Nurses Association, while studies have indicated dramatic decreases in nursing injury claims and days lost after the installation of ceiling lifts (Applied Ergonomics 2006; 37[3]: 377-85).

"We used colour contrast out of the dementia research field to make sure that older adults can pick out where the walls and the ceilings start, where handrails are," van den Broek says. The hospital also boasts $83 \%$ singlepatient bedrooms, improved visibility

\section{"We've only scratched the surface with health care providers to actually practice evidence- based design." - Mark Goodman, vice-president of the Center for Health Design.}

The Royal Jubilee had three pillars for design, says Rudi van den Broek, chief project officer and general manager of special projects at the Vancouver Island Health Authority. "The first was to be elder friendly - a hospital designed for the needs of older adult ... the second, to attract and retain staff to provide the services for those older adults and the third was a focus on sustainability."

Among the two highest-impact features are ceiling-mounted lifts in patient rooms and the creation of colourcontrast environments, van den Broek says. The lifts extend from a patient's bed to the washroom and help nurses of patient rooms from nursing areas, handrails throughout the hospital and plenty of natural light and fresh air (www.viha.ca/patient_care_centre). It has also decreased overhead paging by 99\% from 12700 pages per year to fewer than 200 as a result of Ulrich's research showing that noise has a deleterious effect on patient stress.

"The people that I talk to, the frontline nurses and the hospitalists particularly the doctors that are here $24 / 7$, they just love it. They think it's wonderful, it's calming, it's quiet, it's peaceful, it's healing, it's working very well," van den Broek asserts.
Ulrich says the Royal Jubilee is one the world's premier evidence-based design health care facilities, as evidenced by its award as the Best International Project at the 2010 Public Private Finance Awards.

Despite the advances in evidencebased design, Goodman cautions that "we've only scratched the surface with health care providers to actually practice evidence-based design."

But there's still a need for increased involvement from the health care profession, Goodman believes. "Many doctors get involved when they want to know where plugs are on the head wall," he chides. "If the physicians and leadership of most health care organizations would be so inclined to learn about how the building, the infrastructure can actually help them increase outcomes, ROI [return on investment] and organizational effectiveness, that there would be substantial benefit for society." Nathan Stall, London, Ont.

CMAJ 2012. DOI:10.1503/cmaj.109-4079

Editor's note: Third of a three-part series.

Part I: Private rooms: A choice between infection and profit

(www.cmaj.ca/lookup/doi/10.1503

/cmaj.109-4077).

Part II: Private rooms: The fiscal advantage

(www.cmaj.ca/lookup/doi/10.1503

/cmaj.109-4078).

\section{Swallowing the pharmaceutical waters}

A prescription drug may begin its life as a pretty little pill, but after a brief detour through a human digestive tract and miles of plumbing, some of it ends up in drinking water. Though the levels of pharmaceuticals in drinking water are minuscule, in the parts per trillion, some researchers are concerned that long-term exposure to this low-dose cocktail could prove harmful.
"If you were to drink two litres of water a day for 70 years, at the end of those 70 years, you would have taken $1 \%$ of the normal daily dose of someone taking that prescribed medication. For a variety of standard medications, the concentrations are exceedingly low," says Sébastien Sauvé, associate professor of environmental chemistry at the Université de Montréal in Quebec. "The question we don't have the answer to is: What is the impact of chronic exposure to a very low exposure to a mixture of drugs?"

Researchers have detected all sorts of drugs in drinking water - antibiotics, antidepressants, contraceptives and on down the list. The presence of endocrine disruptors, found in drugs such as steroids, has been shown to seriously mess with hormones in fish, decreasing fertility and even causing 